\title{
PHYSICO-CHEMICAL AND MECHANICAL PROPERTIES OF BLENDED CEMENT PASTES CONTAINING RICE HUSK ASH AND METAKAOLIN
}

\author{
S. A. Abo-El-Enein ${ }^{a}$, H. M. Hammad ${ }^{b}$ T. M. EL-Sokary', S. D. Mekky ${ }^{\text {b }}$ M. E. Mustafab
}

a. Faculty of Sience, Ain Shams University, Cairo, Egypt.

b. Faculty of Sience,Al-Azhar University, Cairo, Egypt.

c. Housing and Building National Building National Research Center, Cairo, Egypt.

\begin{abstract}
This work aims to study the effect of partial substitution of ordinary Portland cement (OPC) by rice husk ash (RHA) and metakaolin (MK) on the physico-chemical and mechanical properties of the hardened OPC-RHA-MK blended cement pastes. $O P C$ was partially replaced by different ratios of $M K(10,15$ and $20 \%)$ and a constant ratio of RHA (5\%) and the resulted cement blends were hydrated in the paste form by using the water/cement ratios required for the standard water of consistency; the pastes thus obtained, were hydrated for 1, 3, 7, 28, and 90 days. At the end of hydration period, the cement pastes were tested for compressive strength, total porosity and hydration kinetic via determination of free lime contents. The phase composition of the formed hydration products was investigated using X-ray diffraction (XRD) and differential thermal analysis (DTA) techniques. It was found that, the substitution of ordinary Portland cement (OPC) by rice husk ash (5\% RHA) enhances the physico-chemical and mechanical properties of the hardened blended cement pastes as compared with the neat OPC. The results of compressive strength indicated slightly higher values for the pastes made of OPC-RHA-MK blends containing 5\% RHA blended with 10, $15 \%$ MK. However, the blended cement paste derived from OPC-RHA-MK blend containing 5\% RHA blended with $20 \%$ MK, for economic reasons, was taken as the most suitable mix containing both RHA and MK. The partial substitution of OPC by RHA and MK leads to higher porosity values with a consequent decrease in the compressive strength values especially during the early ages of hydration. It was found that, the increase of MK content in OPC-RHA-MK blended cement pastes resulted in an increase in water consistency and setting times. Lower values of free lime contents were obtained for OPC-RHA-MK blended cement pastes, with the formation of further additional amounts of CSH, as a result of the pozzolanic reaction. Keywords: Blended Cement, Rice husk ash, Metakaolin, DTA, XRD.
\end{abstract}

\section{INTRODUCTION}

Portland cement concrete is the most widely used human-made commodity on the planet; about 25 billion metric tons are produced globally each year ${ }^{[1]}$. Global Portland cement production currently accounts for $7 \%\left(2 \times 10^{9}\right.$ tones $)$ of anthropogenic carbon dioxide $\left(\mathrm{CO}_{2}\right)$ emissions annually, resulting mainly from production of cement clinker, the active binding ingredient of concrete $^{[2]}$. Because kiln-fired Portland cement is an energy-intensive material, requiring 4-5 GJ per ton of cement ${ }^{[3]}$. About half of these emissions occur through combustion of fossil fuels. The remaining emissions result from calcination of limestone: one $\mathrm{kg}$ of Portland cement clinker releases $0.87 \mathrm{~kg}$ of $\mathrm{CO}_{2}$ to the atmosphere ${ }^{[4]}$. At present, efforts have been made to promote the use of pozzolans to partially replace Portland cement. Pozzolana is a natural or artificial material containing silica in a reactive form. A more formal definition of ASTM C618 ${ }^{[5]}$, describes pozzolana as a siliceous or siliceous and aluminous material which in itself possesses little or no cementitious value but will, in finely divided form and in the presence of moisture, chemically react with calcium hydroxide at ordinary temperatures to form hydrated cementitious properties ${ }^{[6,7]}$. In recent years, many researchers have established that the use of pozzolanic materials, like blast furnace slag, silica fume, metakaolin (MK), fly ash (FA) and rice husk ash (RHA) etc., can not only improve the various properties of concrete, but also contribute to economy in construction costs ${ }^{[8]}$. Rice husks, sometimes called rice hulls, are one of the major agricultural by-products and are the shells produced during the dehusking operation of paddy rice. It constitutes $20 \%$ of the 500 million tons of paddy produced in the world ${ }^{[9]}$. The use of RHA decreases the demand for cement in the construction industry, reduces the cost of concrete production, and reduces the negative environmental impact that $\mathrm{CO}_{2}$ emissions represent in the production of cement. The ash produced by controlled burning of the 
rice husk between $550^{\circ} \mathrm{C}$ and $700^{\circ} \mathrm{C}$ incinerating temperature for $1 \mathrm{~h}$ transforms the silica content of the ash into non-crystalline or amorphous silica ${ }^{[10]}$. Metakaolin (MK) is one of the pozzolanic materials that have been most studied in recent times. MK is an artificial pozzolana obtained from the calcination of kaolinitic clays at temperatures around $700-850{ }^{\circ} \mathrm{C}$. Due to its high pozzolanic activity, the inclusion of $\mathrm{MK}$ improves the mechanical properties and durability of concrete ${ }^{[11]}$.

\section{EXPERIMENTAL}

The materials used in this study were ordinary Portland cement (OPC), rice husk ash (RHA) and Metakaolin (MK). OPC was supplied from Arabian Cement Company, Al Mosalah Portland Cement CEM I- 42.5N; Egypt, Rice husk ash (RHA) was obtained by burning of rice husk in a muffle furnace under controlled burning condition (a heating rate $10^{\circ} \mathrm{C} / \mathrm{min}$ at $650^{\circ} \mathrm{C}$ for 3 $\mathrm{h}$ ), followed by cooling to room temperature in desiccator and ground to pass $90 \mu \mathrm{m}$ sieve. Metakaolin (MK) was prepared by calcination of kaolinite clay which was supplied from Middle East Mining Investments Company, Egypt. Kaolinite clay was calcined in a muffle furnace with a heating rate $10^{\circ} \mathrm{C} / \mathrm{min}$ at $750^{\circ} \mathrm{C}$ for $3 \mathrm{~h}$, to give metakaolin (MK) ; metakaolin recharged from the muffle furnace, cooled to room temperature in a desiccator and ground to pass $90 \mu \mathrm{m}$ sieves. The results of chemical analysis of these materials are shown in Table (1).
Table (1): Chemical oxide composition of starting materials, (wt., \%).

\begin{tabular}{|c|c|c|c|}
\hline $\begin{array}{c}\text { Oxide } \\
\text { contents, }(\%)\end{array}$ & OPC & RHA & MK \\
\hline $\mathrm{SiO} 2$ & 19.94 & 74 & 61.04 \\
\hline $\mathrm{A} 2 \mathrm{O} 3$ & 4.46 & 0.79 & 35.57 \\
\hline $\mathrm{Fe} 2 \mathrm{O} 3$ & 3.6 & 0.27 & 0.34 \\
\hline $\mathrm{CaO}$ & 65.91 & 0.84 & 0.44 \\
\hline $\mathrm{SO} 3$ & 2.73 & 0.68 & 0.24 \\
\hline $\mathrm{MgO}$ & 1.67 & 1.57 & ---- \\
\hline $\mathrm{Na} 2 \mathrm{O}$ & 0.33 & ---- & ---- \\
\hline $\mathrm{K} 2 \mathrm{O}$ & 0.05 & 5.27 & 0.04 \\
\hline $\mathrm{TiO} 2$ & ---- & ---- & 1.18 \\
\hline P2O5 & ---- & 12.10 & 0.33 \\
\hline L.O.I & 1.31 & 5.04 & 0.51 \\
\hline
\end{tabular}

Different dry mixes were prepared by the partial substitution of OPC by different ratios of MK (10, 15 and 20\%) and constant ratio of RHA (5\%). Each dry mix was blended in a porcelain ball mill using three balls for six hours in order to attain a complete homogeneity, then kept in airtight containers. The mix composition of the different OPC-RHA-MK cement blends are given in Table (2).

The water of consistency and setting times (initial and final) of the fresh cement pastes, made of each cement blend, were determined using Vicatapparatus according to ASTM: $\mathrm{C} 191^{[12]}$. To prepare the blended cement pastes made of OPC-RHA-MK blends, an amount of each cement blend was placed on a smooth, non-absor-

Table (2): Mix composition of the various blended cements as well as the optimum water of consistency and setting times of their fresh pastes.

\begin{tabular}{|c|c|c|c|c|c|c|}
\hline \multirow{2}{*}{ Mixes } & \multirow{2}{*}{ OPC, (\%) } & \multirow{2}{*}{ RHA, (\%) } & \multirow{2}{*}{ MK, (\%) } & \multirow{2}{*}{ W/C Ratio } & \multicolumn{2}{|c|}{ Setting times, (min) } \\
\cline { 6 - 7 } & & & & & Initial & Final \\
\hline B & 100 & 0 & 0 & 0.3 & 77 & 170 \\
\hline OR2 & 95 & 5 & 0 & 0.33 & 114 & 234 \\
\hline ORM1 & 85 & 5 & 10 & 0.335 & 138 & 265 \\
\hline ORM2 & 80 & 5 & 15 & 0.345 & 140 & 275 \\
\hline ORM3 & 75 & 5 & 20 & 0.355 & 147 & 290 \\
\hline
\end{tabular}


bent surface, and a crater was formed in the center. The required amount of mixing water (water of consistency) was poured into the crater by the aid of a trowel. The dry cement was slightly trowel over the remaining to absorb the water for about one minute. Continuous and vigorous mixing was made for three minutes then the mixing was completed. The fresh blended cement paste was placed into $2.5 \times 2.5 \times 2.5 \mathrm{~cm}$ cubic moulds, manually pressed into the corners and along the surface of the mould until a homogeneous paste was obtained. After the top layer was compacted and pressed with hand, the surface of the paste was smoothed by the aid of thin edged trowel. Immediately after moulding, the specimens were first cured in a humidity chamber at $100 \%$ R.H. at room temperature $23 \pm 1{ }^{\circ} \mathrm{C}$ for 24 hours. At the end of the moist curing period, the cubic specimens were demoulded and curing was continued under tap water up to $3,7,28$ and 90 days, ASTM: C191 ${ }^{[12]}$. At each hydration time, all pastes were tested for their compressive strength, total porosity, free lime and phase composition of the formed hydration products. A set of three cubic specimens representing the same cement paste and curing time were used for the determination of compressive strength of the hardened paste according to ASTM C-150 ${ }^{[13]}$ and the average value was recorded. The total porosity of the hardened cement pastes was determined according to Copeland and Hayes ${ }^{[14]}$.

After the compressive strength determination, removal of free water was accomplished by using a stopping solution from 1:1 mixture by volume of methyl alcohol and acetone. At any time a representative sample of cement paste, about $10 \mathrm{~g}$, was taken and ground in alumina mortar under the surface of the stopping solution (100 $\mathrm{ml}$ ), then filtered through sintered glass funnel (G4). Washing the content of the funnel was carried out using $50 \mathrm{ml}$ of fresh diethyl ether and dried at $70^{\circ} \mathrm{C}$ in the drying furnace then kept in airtight bottles.

The free lime content, $\mathrm{CaO}(\%)$, was determined by using the glycerol/ethanol extraction method and the mean value of the two independent determinations were recorded, Kondo et al. $^{[15]}$.
Differential thermal analysis (DTA) was carried out using the dried specimens; the apparatus used in the present study was DTA-50 thermal analyzer (Schimadzu Co. Tokyo, Japan). A sample of about $50 \mathrm{mg}$ was used with heating rate for adjusted at $20^{\circ} \mathrm{C} / \mathrm{min}$. under dynamic nitrogen atmosphere. X.ray diffraction technique was carried out on some selected hydrated cement pastes using a Philips diffractometer with a scanning speed of $20^{\circ} \mathrm{C} / \mathrm{min}$. and Ni-filtered $\mathrm{C}_{\mathrm{u}}-\mathrm{K}_{\alpha}$ radiation. The identification of all samples was confirmed by computerized research of the PDF data obtained from the Joint Committee on Powder Diffraction Standards-International Center for Diffraction Data (JCPDS-ICDD), 2001.

\section{RESULTS AND DISCUSSION}

\subsection{Water of consistency and setting time}

The water of consistency and setting times (Initial and final) of the OPC-RHA-MK blended cement pastes are shown in Table (2).It was found that the paste made of OPC-RHA-MK mix which is presented as ORM3 (containing $5 \%$ RHA and $20 \% \mathrm{MK}$ ) possesses the highest water of consistency and setting times (Initial and final) values. The increase in water demand could be attributed to the high fineness of metakaolin and RHA as well as their narrow particle size distribution. The initial and final setting times of OPC-RHAMK blends were affected by the metakaolin content. For cements with $20 \%$ metakaolin content there was a delay in the setting process ${ }^{[16]}$.

\subsection{Compressive strength}

The results of compressive strength of the hardened OPC-RHA-MK blended cement pastes, made with and without the partial replacement of OPC by 5\% RHA (OR2) and different percentages of replacement of OPC by MK (10, 15 and $20 \%$ ) are graphically plotted as a function of curing time up to 90 days in Fig. (1). The results of Fig. (1)show that the compressive strength of the hardened pastes made of all mixes increases continuously with increasing age of hydration. This increase in strength is mainly attributed to the formation and later accumulation of hydration products within the pore system of hardened pastes. At the early ages of hydration (up to 7 days), it is clear that the best mixes are ORM1 
and ORM 2 made with OPC replacement of $5 \%$ RHA together with 10 or $15 \% \mathrm{MK}$, respectively; the pastes made of these two mixes possess almost the same compressive strength values as compared to the neat OPC and higher compressive strength as compared to those of OPCRHA paste (mix OR2). Evidently, the strength results at the early age of hydration can be attributed to the two effects which connected to the development of strength of OPC-RHA-MK blended cement at early ages; these are, (i) the acceleration of OPC hydration, which occurs within the first $24 \mathrm{~h}$, and (ii) the pozzolanic reaction, which has its maximum effect during the later ages of hydration for all MK levels between $5 \%$ and $20 \%{ }^{[17]}$. Metakaolin had a very positive effect on the cement strength especially at the later hydration ages. This may be due to the fact that produced metakaolin as well as the commercial-one gave similar hydration products after 28 days and the pozzolanic reaction was accelerated between 7 and 28 days ${ }^{[16]}$. The hydration products of both OPC and OPC-RHA-MK blends, mainly as calcium silicate hydrates, represent the main binding centers between the remaining unhydrated parts of OPC and artificial pozzolana (MK and RHA) grains. The main conclusions derived from the results of compressive strength obtained are summarized as follows:

(i) The blended cement derived from OPCRHA mix OR2 represents the most suitable mix containing RHA as a partial replacement of OPC.

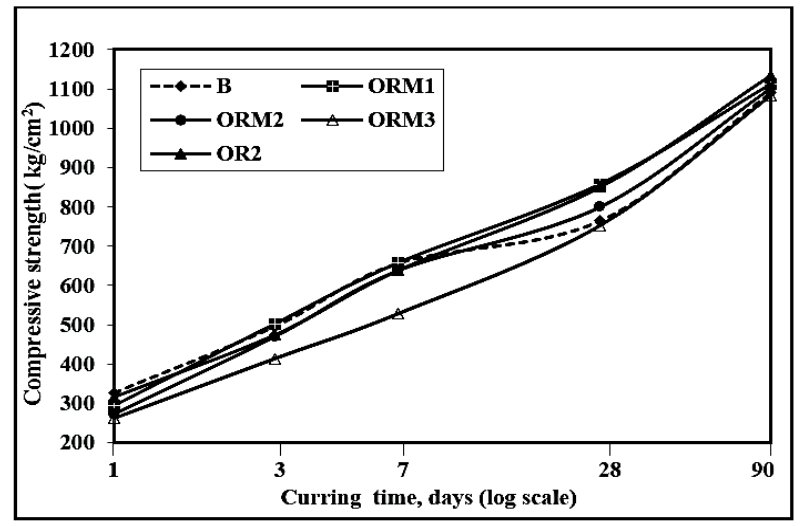

Fig.(1):Compressive strength $(\mathrm{kg} / \mathrm{cm} 2)$ of blended cement pastes made of the neat OPC,OPC-RHA and OPC-RHA-MK blends as a function of curing time. (ii) The blended cement derived from OPCRHA-MK mix ORM3, for economic reasons, the most suitable mix containing both RHA and MK as partial replacements of OPC.

These two conclusions are based on the basic of the reasonable strength values of the hardened blended cement pastes made of OR2 and ORM3 mixes; these values are slightly lower than those of the OPC at the early ages of hydration, while at the later ages of hydration, higher values of strength are obtained for these blended cement pastes as compared to those of the neat OPC paste.

\subsection{Total porosity}

The incorporation of RHA and/or $\mathrm{MK}$ as partial replacements of OPC resulted in a very dense microstructure of the hardened blended cement pastes with lower total porosity in comparison with the neat OPC paste ${ }^{[18]}$. The results of total porosity of hardened blended cement pastes, made of OPC-RHA of mix OR2 with different replacements by MK (10,15 and 20\%), at the various ages of hydration up to 90 days are graphically plotted as a function of curing time in Fig. (2).It is clear that the total porosity of the hardened cement pastes made of all mixes decreases with the increase of curing time due to the progress of hydration which leads to filling of large fraction of the total pore system of the hardened cement pastes. Obviously, the results of Fig (2) show that the total porosity increases with the increase the level of OPC replacement by MK up to 7 days of hydration compared to OPC paste with and without RHA; because the total pore volume decreases with an increasing rate up to 14 days $^{[19]}$. The incorporation of MK to OPC-RHA blend (Mix OR2) enhances the pozzolanic reaction with the free $\mathrm{CH}$ liberated from OPC hydration especially at the early ages of hydration. At the longer ages of hydration (2890 days), the hardened pastes made of all mixes of OPC-RHA with and without MK exhibit lower porosity values than those of the neat OPC paste.

\subsection{Free lime content:}

Kinetics of hydration was studied by the determination of free lime $(\mathrm{CaO}, \%)$ at the different 


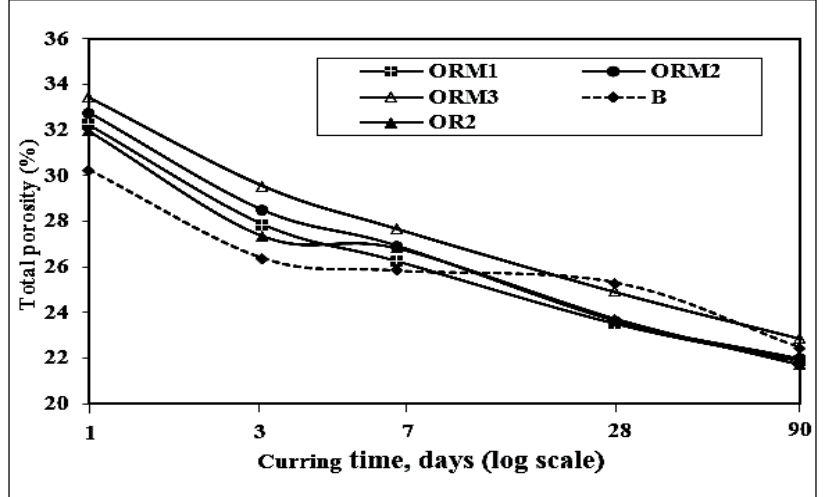

Fig. (2):The total porosity of the hardened blended cement pastes made of the neat OPC, OPC-RHA and OPC-RHA-MK blends at the different curing ages (days).

ages of hydration. Evidently, the hydration of the neat OPC paste is associated with a continuous liberation of free portlandite $(\mathrm{CH})$ from the hydration of OPC clinker phases ${ }^{[20]}$. The free lime contents obtained for the hardened blended cement pastes made from OPC-RHA blend (OR2) with different percentages of replacement of OPC by MK (10, 15 and 20\%) were determined at the different ages of hydration up to 90 days and these are graphically plotted as a function of curing time in Fig. (3). It is clear from the results of Fig. (3) that, the free lime contents $(\mathrm{CaO}, \%)$ obtained for the various blended cement pastes, made of OPC-RHA and OPC-RHA-MK mixes, increase with increasing age of hydration up to 3-days; this is followed by a gradual decrease with increasing age up to 90-days of hydration. The values of the free lime content obtained for the various OPC-RHA-MK blended cement pastes represent a net effect of the amount of free lime liberated during OPC hydration and the free lime consumed as a result of the pozzolanic reaction between $\mathrm{CH}$ and RHA and/or MK. At the early ages of hydration (up to 3 days), the free lime liberated from OPC fraction exceeds the free lime consumed by the pozzolanic reaction; while at the later ages of hydration, however, the amount free lime consumed by the pozzolanic reaction exceeds the amount of free lime liberated duringOPC hydration.

\subsection{Differential thermal analysis (DTA)}

The DTA thermograms obtained for the hardened of OPC (B), OPC-RHA-MK mixes (ORM1,

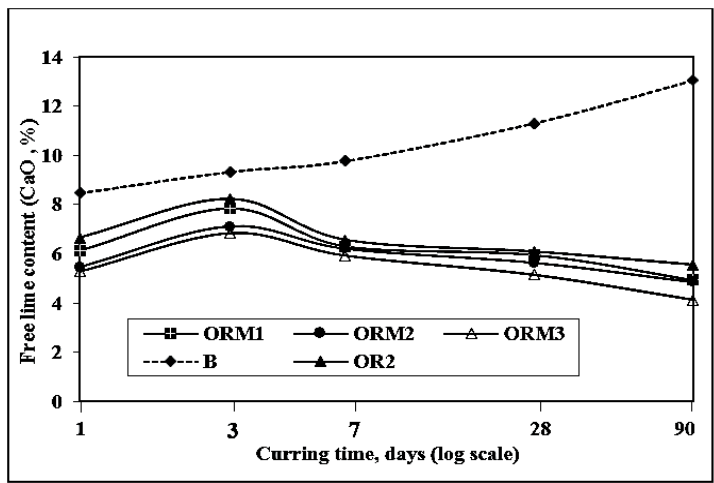

Fig. (3): Free lime content of the hardened blended cement pastes made from the neat OPC, OPC-RHA and OPC-RHAMK blends as a function of curing ages time.

ORM2 and ORM3) and OPC-RHA mix (OR2) after 7 and 90 days of hydration are shown in Figs. (4-7). The first endothermic peak located at about $80-120^{\circ} \mathrm{C}$ characterizes the removal of free water and the decomposition of the nearly amorphous calcium silicate hydrates, mainly as $\mathrm{CSH}(\mathrm{I})$ and $\mathrm{CSH}(\mathrm{II})$, as well as calcium sulphoaluminate hydrates. The second endothermic peak observed at about $140-170^{\circ} \mathrm{C}$ represents the decomposition of calcium aluminate hydrates, mainly as $\mathrm{C}_{4} \mathrm{AH}_{13}$, as well as the crystalline $\mathrm{CSH}$. The third endothermic peaklocated at about $440-470^{\circ} \mathrm{C}$ is characteristic for the decomposition of $\mathrm{CH}$. The last two endothermic peaks appeared at 700-740 and $750-810{ }^{\circ} \mathrm{C}$ represent the decomposition of amorphous $\mathrm{CaCO}_{3}$ and its crystalline form, respectively. The endotherms characteristic for calcium silicate hydrates (CSH) becomes more distinguishable for the hardened OPC-RHA-MK blended cement pastes (ORM1, ORM2 and ORM3) specially after 7-day of hydration and extended to the later age of hydration (90-days) which exhibit a marked decrease in the intensity of portlandite peak and increasing intensities of CSH peaks; this is due to the pozzolanic reaction of the amorphous silica in RHA and amorphous silica and alumina in MK with the free lime released from OPC hydration. These results are in agreement with the data obtained for the free lime content reported before in this investigation. This larger consumption of $\mathrm{CH}$ is also confirmed from the results of free lime content which is strongly reduced at the lat- 
er ages of hydration. In conclusion, the addition of blending materials such as pozzolana (RHA and $\mathrm{MK}$ ) can effectively reduce the $\mathrm{CH}$ content of the hardened OPC paste.

\subsection{X-ray diffraction (XRD) analysis:}
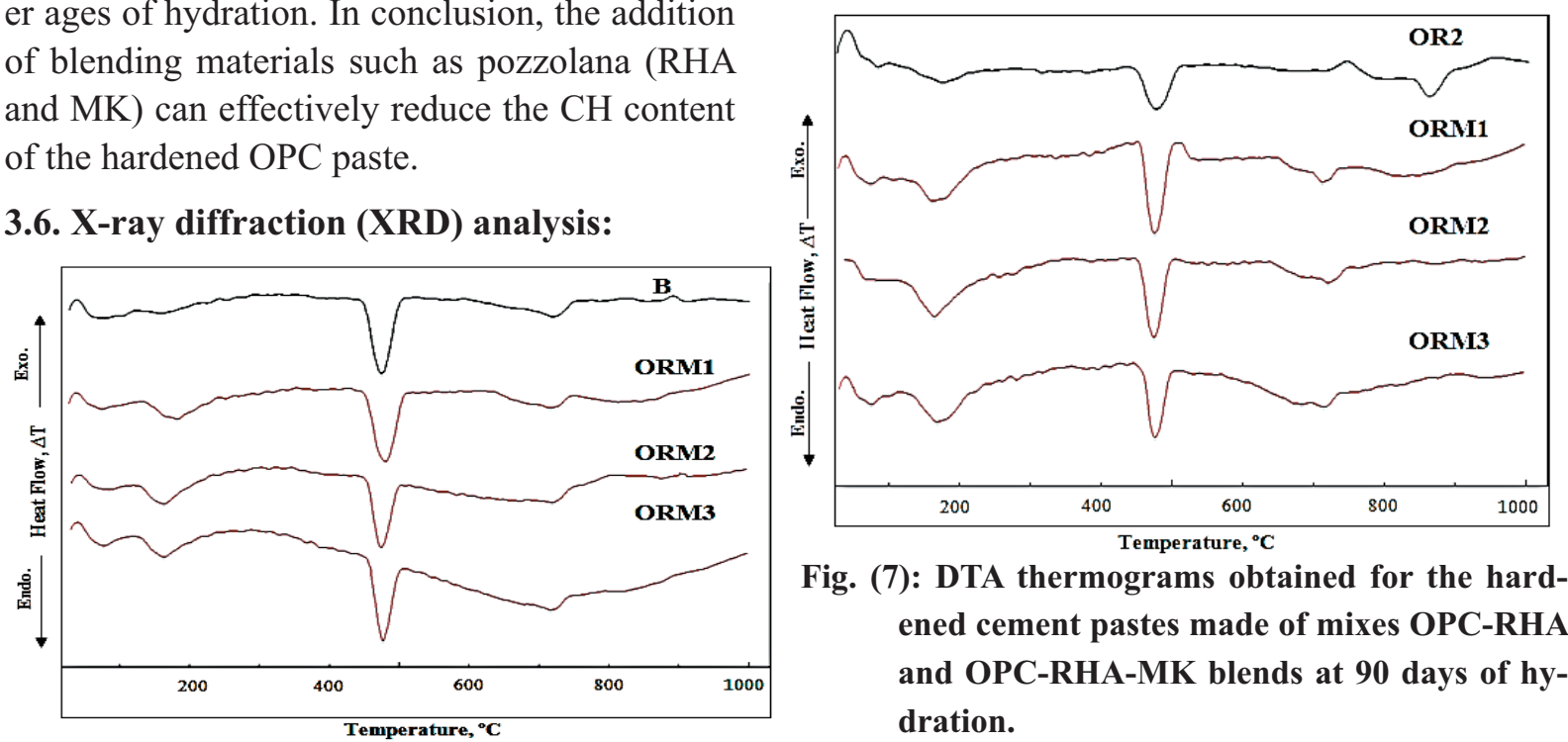

Fig. (7): DTA thermograms obtained for the hardened cement pastes made of mixes OPC-RHA and OPC-RHA-MK blends at 90 days of hydration.

Fig. (4): DTA thermograms obtained for the hardened cement pastes made of the neat OPC and OPC-RHA-MK blends at 7 days of hydration.

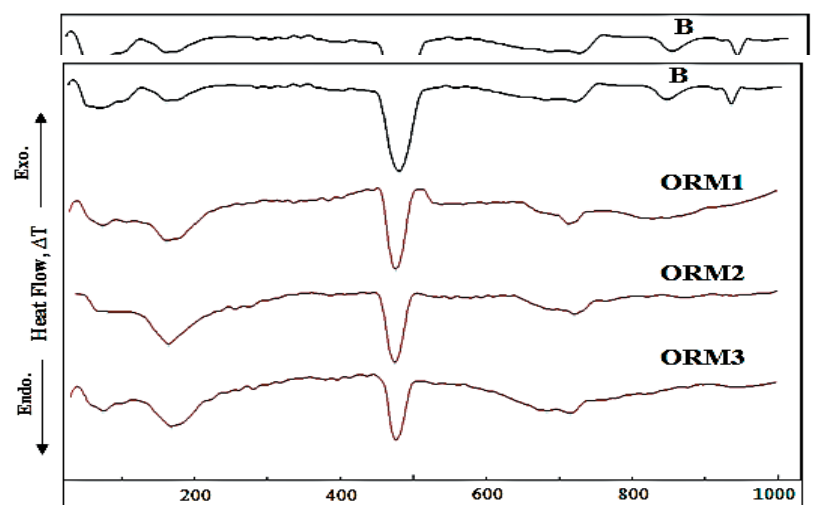

The XRD patterns obtained for the hardened pastes, made of the neat OPC (mix, B), OPC substituted with $5 \%$ rice husk ash (mix, OR2) and OPC substituted with 5\%RHA and different ratios of MK (mixes, ORM1, ORM2 and ORM3), after 7 and 90 days of hydration are shown in Figs. (8-11). Obviously, the XRD patterns shown in Figs. (8-11) indicate the presence of the main hydration products which are calcium silicate hydrates $(\mathrm{CSH})$, calcium aluminosilicate hydrates (CASH) and calcium hydroxide $(\mathrm{CH})$, in addition to the remaining unhydrated parts of OPC clinker phases $\left(\mathrm{C}_{3} \mathrm{~S}\right.$ and $\left.\beta-\mathrm{C}_{2} \mathrm{~S}\right)$ as well as the quartz phase in case of the hardened OPC-RHA-

Fig. (5):DTAthermograms obtained for the hardened cement pastes made of the neat OPC and OPCRHA-MK blends at 90 days of hydration.

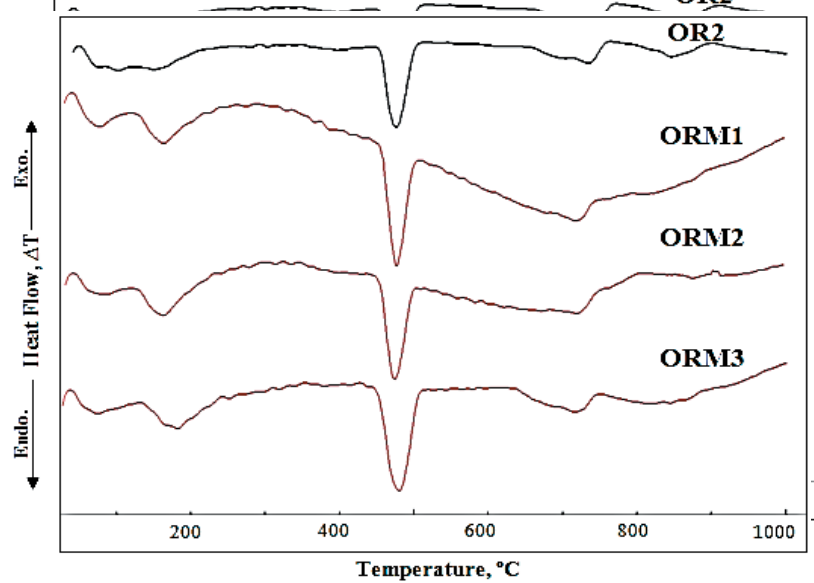

Fig. (6): DTA thermograms obtained for the hardened cement pastes made of mixes OPC-RHA and OPC- RHA-MK blends at $\mathbf{7}$ days of hydration.

MK blended cement pastes. In addition, $\mathrm{CASH}$ and $\mathrm{CAH}$ phases were observed for the OPCRHA-MK pastes where MK appeared to have a catalyzing effect on OPC hydration, leading to an acceleration in the reaction rates; an increase in cumulative heat evolved was observed in a previous publication during early hydration, and for some cements apparently an increased intensity in heat evolved during certain periods of early hydration ${ }^{[21]}$. However, the results show a gradual decrease of peak intensities characteristic for $\mathrm{CH}$, accompanied by a corresponding increase of the peak intensities characteristic for calcium silicate hydrates (CSH), was observed in the XRD diffractograms obtained for OPCRHA-MK blended cement pastes; this increase is related to the amount of MK in OPC-RHAMK blends pastes during the first 7-days of hy- 
dration. The results indicate also that MK has a fast pozzolanic activity at early ages of hydration; it does consume higher amounts of $\mathrm{CH}$ liberated from the hydration of OPC at early ages of hydration. At the later ages of hydration, the peaks of the anhydrous cement components $\left(\mathrm{C}_{3} \mathrm{~S}\right.$ and $\left.\beta-\mathrm{C}_{2} \mathrm{~S}\right)$ are almost disappeared. Since there is a clear decrease of the $(\mathrm{CH})$ content at the longer ages of hydration (beyond 3 days), it is concluded that it was consumed in its pozzolanic interaction with RHA and MK. This is also confirmed by the decrease in intensities of the main $\mathrm{CH}$ peaks, especially after 90-days of hydration. This is attributed to the formation of additional amounts of calcium silicate hydrates (CSH-II) and calcium aluminate hydrates $(\mathrm{CAH})$.

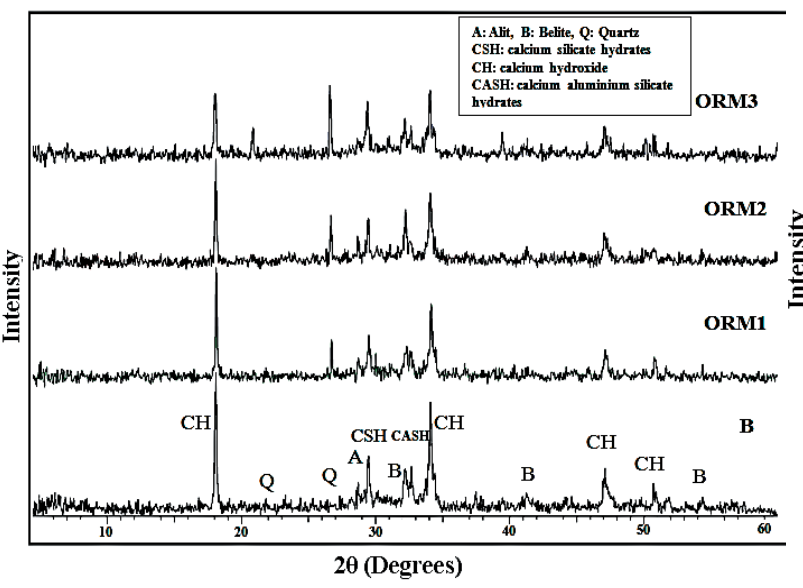

Fig. (8): The XRD patterns obtained for the hardened cement pastes made from theneat $O P C$ and mixesORM1, ORM2 \& ORM3at 7- days of hydration.

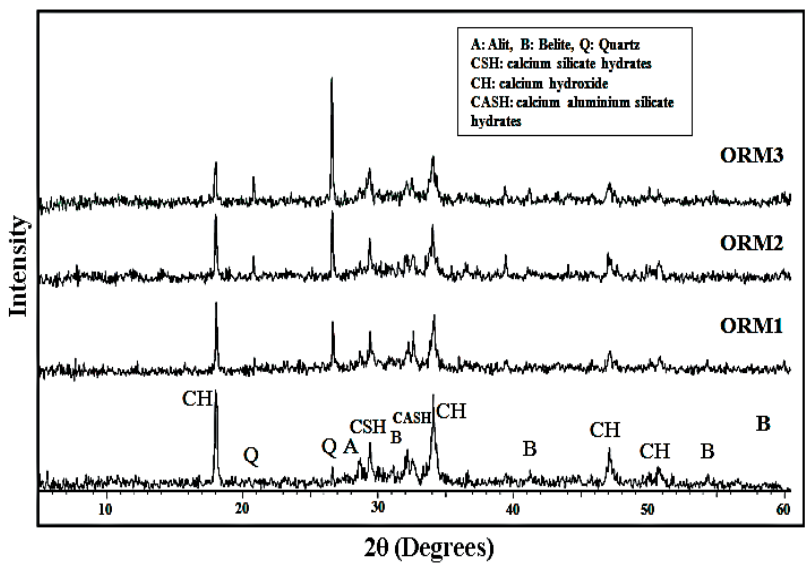

Fig. (9):The XRD patterns obtained for the hardened cement pastes made from theneat OPC and mixesORM1, ORM2 \& ORM3 at 90-days of hydration.

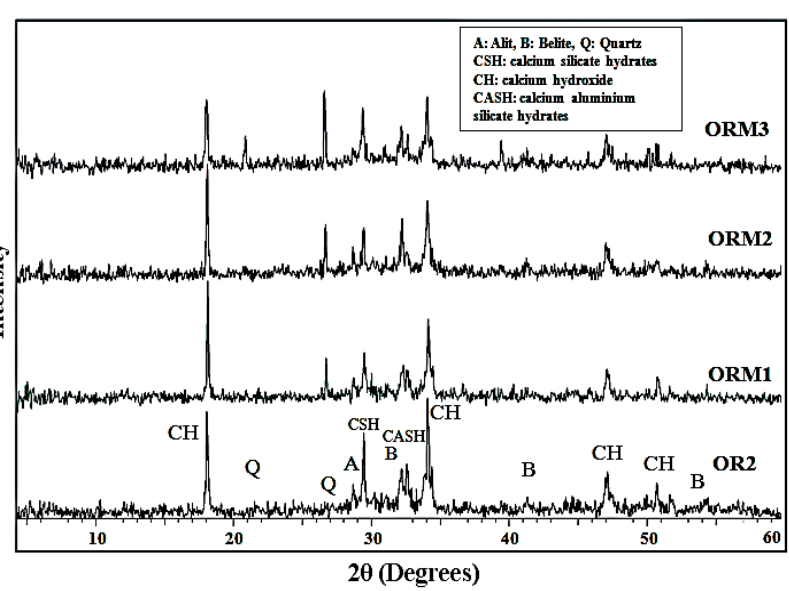

Fig. (10): The XRD patterns obtained for the hardened cement pastes made from the mixes OR2, ORM1, ORM2 and ORM3 at 7-days of hydration.

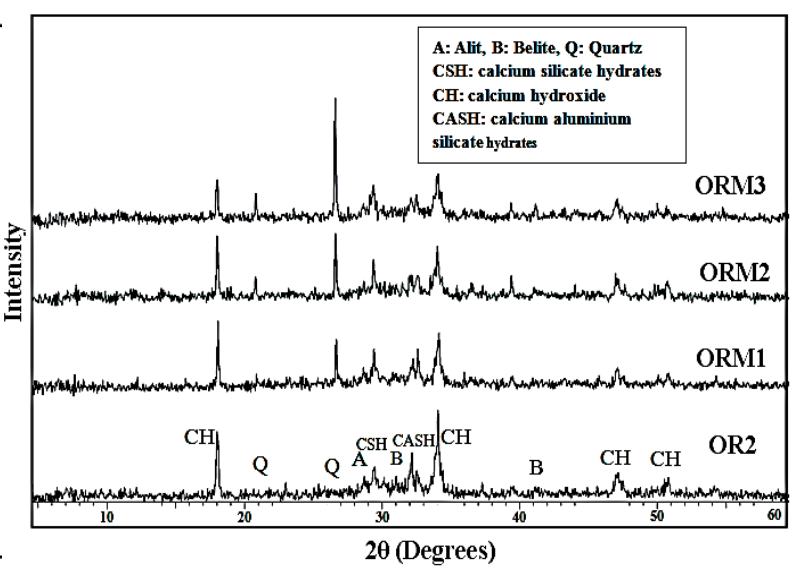

Fig. (11): The XRD patterns obtained for the hardened cement pastes made from themixes OR2, ORM1, ORM2 and ORM3) at 90-days of hydration.

\section{REFERENCES}

[1]WBCSD, "The cement sustainability initiative: recycling concrete". In: Klee H, editor. Geneva (Switzerland): World Business Council for Sustainable Development, p. 1-42 (2009).

[2]IEA-WBCSD, “Cement Technology Roadmap 2009 - Carbon emissions reductions up to 2050”, (2009).

[3]Mehta PK. "Reducing the environmental impact of concrete",Concr. Inter, 61-66(2001).

[4]WBCSD-CSI, “Cement Industry Energy and CO2 Performance", Washington, DC,(2009).

[5]ASTM C618,"Standard specification for coal fly ash and raw or calcined natural Pozzolana for use as a mineral admixture in concrete", ASTM C618, Annual Book ASTM Stand (04-02), 313 (2001). 
[6]Singh M., GargM.,"Reactive Pozzolana from Indian clays: their use in cement mortars",Cem. Concr. Res., 36, 1907 (2006).

[7]Tseng YS, Huang CL, Hsu kc. "The pozzolanic activity of a calcined waste FCC catalyst and its effect on the compressive strength of cementitious materials", Cem. Concr. Res., 35, 787 (2005).

[8]Amrutha, GopinathaNayak, Mattur C. Narasimhan and Rajeeva S.V. "Chloride-Ion Impermeability of SelfCompacting High-Volume Fly Ash Concrete Mixes". Inter. J. Civil \& Environ. Engin, IJCEE-IJENS, 11(4), 29- 35(2009).

[9]Bhanumathidas, N., \& Mehta, P. K.,"Concrete mixtures made with ternary blended cements containing fly ash and rice husk ash", In V. M. Malhotra (Ed.), International conference proceeding seventh CANMET, Chennai, India, 1, 391(2004).

[10] Bui D., Hu J. and Stroeven P., "Particle size effect on the strength of rice husk ash blended gap-graded Portland cement concrete". Cem.Conc. Compos., 27, 366(2005).

[11]Hong-Sam Kim, Sang-Ho and Han-Young Moon, "Strength properties and durability aspects of high strength concrete using Coreanmetakaolin", Constr. Build. Mater., 21, 1237 (2007).

[12]ASTM Designation C-191.,"Standard test method for normal consistency and setting of hydraulic cement", Annual Book of ASTM Standards, 4, 1(2008).

[13]ASTM Designation C-150. "Standard test methods for compressive strength of hydraulic cement". ASTM Standards,(2007).

[14]Copeland LE, Hayes TC. "Porosity of hardened Portland cement pastes",J.Amer. Concr.; 27, 633-640(1956).

[15]Kondo R, Abo-El-Enien SA andDaimon M. "Kinetics and mechanisms of hydrothermal reaction of granulated blast furnace slag", Bull. Chem. Soci., 48, 226 (1975).

[16]Badogiannis, E., Kakali, G., Dimopoulou, G., Chaniotakis, E., Tsivilis, S., "Metakaolin as a main cement constituent: exploitation of poor Greek kaolins", Cem. Concr. Compos., 27 (2), 203 (2005).

[17]Wild S, Khatib JM, Jones A. "Relative strength, pozzolanic activity and cement hydration in superplasticizedmetakaolin concrete", Cem. Conc. Res., 26, 1544(1996).

[18]Poon C.S., Kou S.C. and LamL., "Compressive strength, chloride diffusivity and pore structure of high performance metakaolin and silica fume concrete", Construct. Build. Mater.,20 (10), 865 (2006).

[19]Khatib J.M., Wild, S., "Pore size distribution of metakaolin paste”. Cem. Concr. Res.,26(10),1553 (1996).

[20]M. S. Amin, S. A. Abo-El-Enein, A. Abdel Rahman and Khaled A. Alfalous, "Artificial pozzolanic cement pastes containing burnt clay with and without silicafume",JTherm Anal Calorim 107, 1115 (2012).

[21]Lagier F., Kurtis K.E., "Influence of Portland cement composition on early age reactions with metakaolin". Cem. Concr. Res.,37 (10), 1417 (2007). 